\title{
Absorption Spectral Studies on Naphthyl Pyridyl Pyrazole (NPP) in Mixed Solvent Systems
}

\author{
KHALED MUFTAH ELSHERIF* , ASHRAF EL-HASHANI, ABDELMENEIM EL-DALI, \\ OTMAN DAKHIL, ADEL NAJAR and MOHAMED ALGERIANI
}

Benghazi University, Faculty of Science, Chemistry Department, Benghazi-Libya elsherif27@yahoo.com

Received 12 March 2014 / Accepted 29 March 2014

\begin{abstract}
The synthesis and absorption spectroscopy of the bichromophore 1-[(2-naphthyl) methyl]-3-(2-pyridyl)-1H-pyrazole (NPP) are reported. The absorption spectra of NPP have been studied in mixed solvents, in which the spectra shows two main peaks due to $\pi \rightarrow \pi^{*}$ transition. The positions and intensities of the absorption band of NPP are sensitive to the solvent polarity. The spectral shifts are attributed to solvent-solute interactions in terms of hydrogen bonding effects. However, it is frequently found, that the dielectric properties of polar mixtures observe influence on wavelength of maximal absorption and the absorption intensity.
\end{abstract}

Keywords: Solvent effect, Absorption spectra, Naphthyl pyridyl pyrazole

\section{Introduction}

Pyrazoles $^{1}$ have been used as versatile ligands for a variety of coordination compounds ranging from bioinorganic models ${ }^{2}$ and antitumor agents ${ }^{3}$ to materials with efficient luminescent properties ${ }^{4}$. Synthesis and design multi-dentate ligand based on bis and more 3(2-pyridyl) pyrazole arms in coordination chemistry has attracted a great interest in supramolecular 3-(2-pyridyl) pyrazole coordination chemistry due to the various structures of the final product ${ }^{5-8}$.

UV/Vis spectroscopy is routinely used in analytical chemistry for the quantitative and qualitative determination of different analytes, such as transitional metal ions, highly conjugated organic compounds and biological macromolecules. Spectroscopic analysis is commonly carried out in solutions but solids and gases may be also studied. When absorption spectra are measured in solvents of different polarity, it is found that the position, intensities, and shapes of the absorption bands are usually altered by these solvents. These changes are due to the result of physical intermolecular solute-solvent interaction forces (such as ion-dipole, dipole-dipole, dipole-induced dipole, hydrogen bonding, etc.), which above all tend to alter the energy difference between ground and excite state of the absorbing species containing the chromophore ${ }^{9-14}$. 
Study of the effect of solvents on the electronic absorption and fluorescence spectra of a variety of molecules (e.g. anthraquinone derivatives, azo compounds, azo disperse red dyes) form an important subject for research in last years because can play a significant role in the photophysics of the excited states. Several reports are now available on the correlation of UV absorption frequencies with the solvent parameter ${ }^{15}$. Anomalous shifts of electronic absorption bands of unsaturated molecules to shorter wavelength on changing from the solvent of low dielectric constant to one of higher dielectric constant and vice versa had been a subject of several studies ${ }^{11}$. This work aims to prepare and study the effect of mixed solvents on the electronic absorption spectrum of 1-[(2-Naphthyl) methyl]-3-(2-pyridyl)-1Hpyrazole (NPP) (Scheme 1).<smiles>c1ccc(-c2ccn(Cc3ccc4ccccc4c3)n2)nc1</smiles>

Scheme 1. Structure of 1-[(2-Naphthyl) methyl]-3-(2-pyridyl)-1H-pyrazole (NPP)

\section{Experimental}

All the chemicals and solvents used in the preparation and spectroscopic studies were A. R. products which used as received without further purification.

\section{Synthesis of the NPP}

A mixture of 2-(bromomethyl) naphthalene $(0.50 \mathrm{~g}, 1.76 \mathrm{mmol}), 3$ - (2- pyridyl) pyrazole (0.256 g, $1.76 \mathrm{mmol})$, aqueous $\mathrm{NaOH}(10 \mathrm{M}, 10 \mathrm{~mL})$ and tetrahydrofuran (THF) $(50 \mathrm{~mL})$ was heated at reflux with stirring for $24 \mathrm{~h}$. After cooling, the organic layer was washed with water and then dried over $\mathrm{MgSO}_{4}$. Removal of the solvent in vacuum afforded pale yellow oil which afforded a white powder on recrystallization from $\mathrm{CH}_{2} \mathrm{Cl}_{2} . \mathrm{Et}_{2} \mathrm{O}(0.37 \mathrm{~g}, 74 \%)$.

ES-MS mass spectrum: m/z $286(100 \%)$. 1HNMR $\left(250 \mathrm{MHz}, \mathrm{CDCl}_{3}\right): 5.87(2 \mathrm{H}, \mathrm{s}$, $\left.\mathrm{CH}_{2}\right), 8.56$ (1 H, d, pyridyl H6), $7.18(1 \mathrm{H}, \mathrm{t}$, pyridyl H5), 7.45(1H, t, pyridyl H4), $7.23(1 \mathrm{H}$, d, pyridyl H3), $7.07(1 \mathrm{H}$, d, pyazolyl $\mathrm{H} 5), 6.80(1 \mathrm{H}$, d, pyrazolyl $\mathrm{H} 4), 7.18(1 \mathrm{H}, \mathrm{d}$, naphthyl H3), 7.94-8.01(2H, m, naphthyl H4, H5, H8), $7.46(1 \mathrm{H}$, d, naphtyl, 1H), 7.55 7.58(2H, m, naphthyl, H6, H7). ES mass spectrum: m/z $286(\mathrm{MH}+)$. X-ray quality crystals were grown by slow diffusion of diethyl ether vapor into a concentrated $\mathrm{CH}_{2} \mathrm{Cl}_{2}$ solution of NPP.

\section{Preparation of NPP solutions}

Stock solution $\left(6.5 \times 10^{-4} \mathrm{M}\right)$ of NPP sample was prepared by weighing $0.0920 \mathrm{~g}$ of NPP and dissolved in $500 \mathrm{~mL}$ methanol. Series concentrations of NPP $(4.35,3.26,2.61,2.17$, $1.86 \times 10^{-5} \mathrm{M}$ ) were prepared by dilution with a suitable volume of the examined solvent.

\section{Absorption spectra measurements}

The absorption spectra of NPP solutions were recorded using single beam UV-Visible spectrophotometer from Biochrom Ltd, Cambridge CB4 of J England with a matched pair of quartz cuvettes ( $1 \mathrm{~cm}$ in optical path length).

\section{Results and Discussion}

The UV spectra for the NPP in methanol were recorded and compared with the spectra of NPP in different ratios of methanol with other solvents that have different dielectric constants. The examined solvents were: water, ethyl acetate, chloroform and carbon tetrachloride. The comparison was made in terms of $\lambda_{\max }$ shift (red or blue shift) and absorption intensity ( $\varepsilon$, molar absorptivity). 


\section{Absorption spectrum of NPP in methanol}

The spectra of $2.5 \times 10^{-5} \mathrm{M}$ of NPP in methanol is shown in Figures 1 . Two absorption maxima can be seen at $274 \mathrm{~nm}$ and $302 \mathrm{~nm}$. These two peaks are due to $\pi \rightarrow \pi^{*}$ (Table 1). The compound has two chromophores; naphthalene system $(\mathrm{N})$ and pyridine - pyrazole system (PP) (Scheme 2). The peak at $274 \mathrm{~nm}$ can be attributed to PP system and the peak at $302 \mathrm{~nm}$ is attributed to $\mathrm{N}$ system ${ }^{16}$.<smiles>Cc1ccc2ccccc2c1</smiles>

Scheme 2. Naphthalene $(\mathrm{N})$ and pyridine - pyrazole (PP) systems

The $\mathrm{N}$ system has only $\pi$ conjugated electrons as in Scheme 3 but PP system has both $\pi$ and $n$ electrons which are also conjugated as in Scheme 4. The presence of lone pairs of electrons on the nitrogen atoms does not change the $\pi-\pi^{*}$ nature of the transitions of the system. These lone pairs are indeed involved directly in $\pi$ bonding with the aromatic system and therefore the transition $\pi \rightarrow \pi^{*}$ for this system will be affected significantly by the polarity of the solvent as seen later.

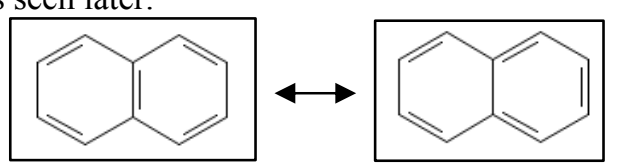

Scheme 3. Resonance structures of N system

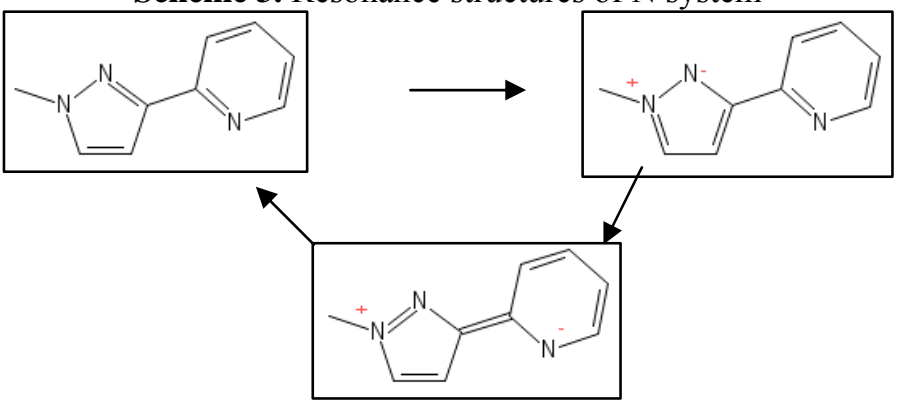

Scheme 4. Resonance structures in PP system

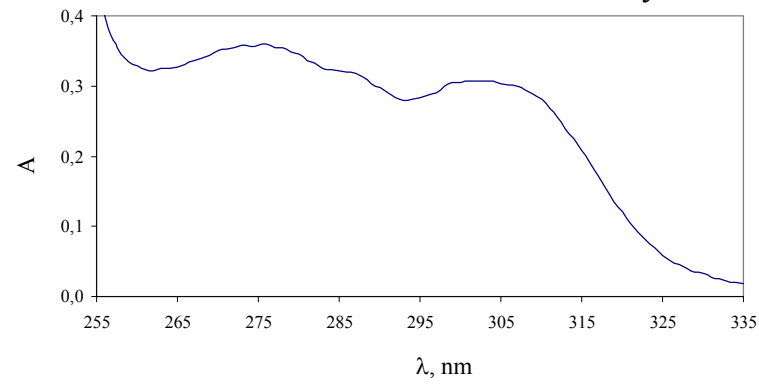

Figure 1. Absorption spectrum of NPP $\left(2.5 \times 10^{-5} \mathrm{M}\right)$ in methanol

The molar absorptivities of NPP in methanol at $\lambda_{\max }=274$ and $302 \mathrm{~nm}$ have been determined and shown in Table 1. The high molar absorptivities indicates the transitions are of $\pi \rightarrow \pi^{*}$ type. 
Table 1. Molar absorptivity values of NPP in methanol and different mixed solvents

\begin{tabular}{ccc}
\hline Solvent & $\lambda_{\max }, \mathrm{nm}$ & $\varepsilon, \mathrm{L} \mathrm{mol}^{-1} \mathrm{~cm}^{-1}$ \\
\hline Methanol & 274 & 14055 \\
Methanol:Water & 269 & 20709 \\
Methanol:Ethyl Acetate & 285 & 10742 \\
Methanol:Chloroform & 279 & 7277 \\
\hline
\end{tabular}

\section{Absorption spectra of NPP in different ratios of methanol: water}

The spectra of NPP in different ratios of methanol to water have been recorded and shown in Figure 2. A small blue shift; as the percent of water increases, can be seen in the peak at $\lambda=274$ $\mathrm{nm}$ and also an increase in absorption intensity. However, this peak is due to PP system which contains ' $n$ ' electrons on nitrogen atoms involved in $\pi$ conjugated system. The electron density on the nitrogen atom is reduced by two opposite factors; one due to hydrogen bond formation which increases with water percent in the mixture and the other factor is due to contribution in $\pi$ conjugation system which in terns decreases with water percent. However, more conjugation shifts the peak to longer wavelength (red shift) but as hydrogen bond formation increases (as in water solvent) the conjugation will decrease and therefore a blue shift is seen.

Also, the molar absorptivity value in methanol: water is higher than in methanol (Table 1). However, the molar absorptivity depends on the probability of the transition; as the probability increases the molar absorptivity will increase. As water percent increases the contribution of $n$ electrons from nitrogen atom in $\pi$ conjugation system will decrease as a result of the formation of hydrogen bond between the NPP and water molecules. This means a more pure $\pi \rightarrow \pi^{*}$ transition will occur and therefore the probability of this transition will be increased.

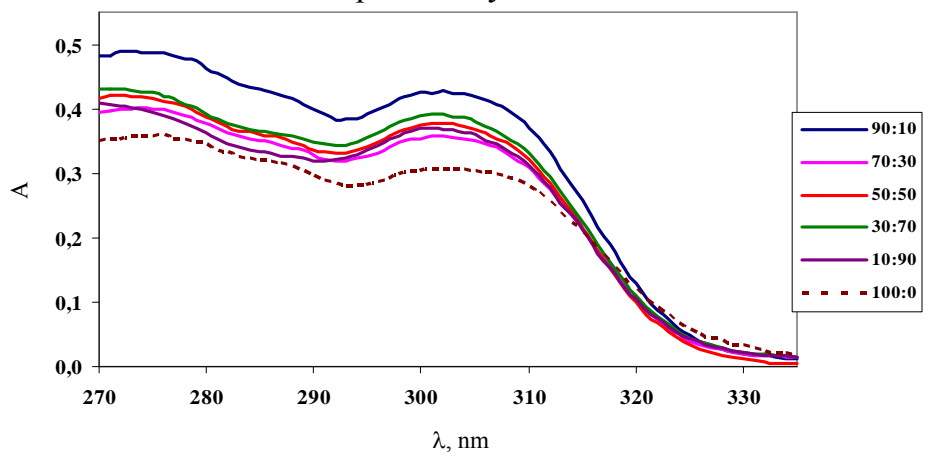

Figure 2. Absorption spectra of NPP in mixed methanol and water solvent

The shift of the peak as a function of water percent is shown in Figure 3. As the water percent increases the extent of the blue shift also increases which is related to the extent in hydrogen bond formation. The values of molar absorptivities are shown in Table 1.

\section{Absorption spectra of NPP in different ratios of methanol: ethyl acetate}

The spectra of NPP in different ratios of methanol to ethyl acetate have been recorded and shown in Figure 4. A small red shift; as the percent of ethyl acetate increases, can be seen in the peak at $\lambda=274 \mathrm{~nm}$. Also, there is a decrease in absorption intensity compared with the spectra in methanol.

The ability of NPP to form hydrogen bond with the solvent decreases as the percent of ethyl acetate increases and therefore conjugation in $\pi$ PP system will increase and then a red 
shift is seen. The decrease in molar absorptivity values as a percent of ethyl acetate increases is because of increasing the contribution of $n$ electrons from nitrogen atom in the $\pi$ conjugation which results in decreasing the probability of $\pi \rightarrow \pi^{*}$ transition.

- H2O $\triangle$ MeCOOEt $\triangle$ CHCl3 $\times$ CCl4 $-*-$ Only MeOH

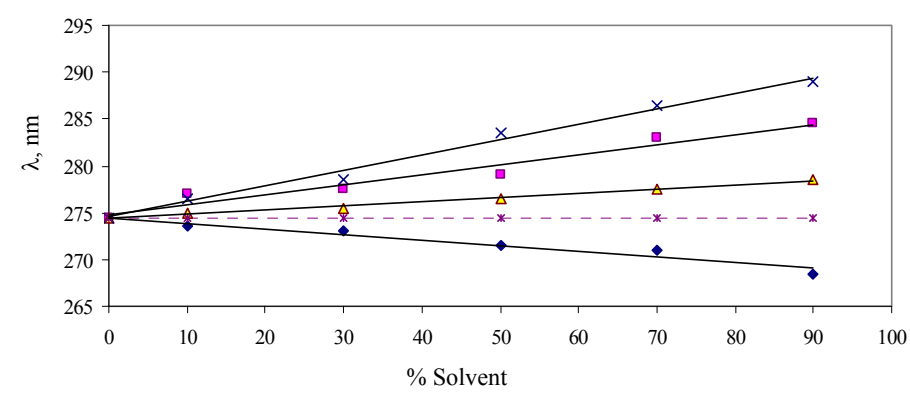

Figure 3. The relationship between $\lambda_{\max }$ and $\%$ added solvent

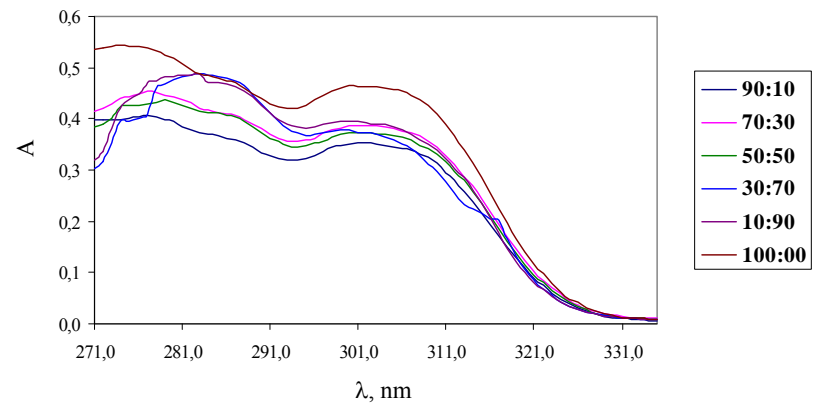

Figure 4. Absorption spectra of NPP in mixed methanol and ethyl acetate solvent

The shift of the peak as a function of ethyl acetate percent is shown in Figure 3. As the ethyl acetate percent increases the extent of the red shift also increases which is as a result of the increase in conjugation. The values of molar absorptivities are shown in Table 1.

\section{Absorption spectrum of NPP in different ratios of methanol: chloroform}

The spectra of NPP in different ratios of methanol to chloroform have been recorded and shown in Figure 5. A small red shift; as the percent of chloroform increases, can be seen in the peak at $\lambda=274 \mathrm{~nm}$. Also, there is a decrease in absorption intensity compared with the spectra in methanol.

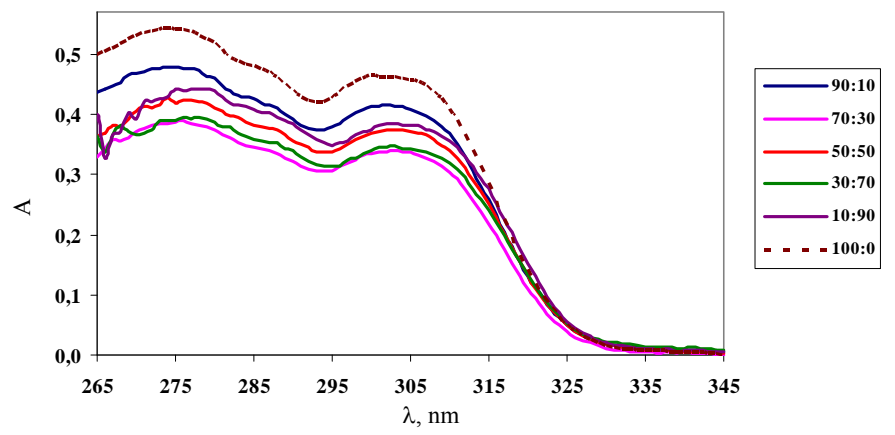

Figure 5. Absorption spectra of NPP in mixed methanol and chloroform solvent 
The ability to form hydrogen bond; as the percent of chloroform increases, is decreased and therefore the contribution of $\mathrm{n}$ electrons from the nitrogen atom is increased and therefore a red shift is seen and also the probability of $\pi \rightarrow \pi^{*}$ transition is become lower which is showed by the values of molar absorptivity.

The shift of the peak as a function of chloroform percent is shown in Figure 3. As the chloroform percent increases the extent of the red shift also increases which is as a result of the increase in conjugation. The values of molar absorptivities are shown in Table 1.

\section{Absorption spectrum of NPP in different ratios of methanol: Carbon tetrachloride}

The spectra of NPP in different ratios of methanol to carbon tetrachloride have been recorded and shown in Figure 6. A significant red shift; as the percent of carbon tetrachloride increases, can be seen in the peak at $\lambda=274 \mathrm{~nm}$. Also, there is a decrease in absorption intensity compared with the spectra in methanol.

The ability to form hydrogen bond; as the percent of carbon tetrachloride increases, is decreased and therefore the contribution of $n$ electrons from the nitrogen atom is increased and therefore a red shift is seen and also the probability of $\pi \rightarrow \pi^{*}$ transition is become lower which is showed by the values of molar absorptivity.

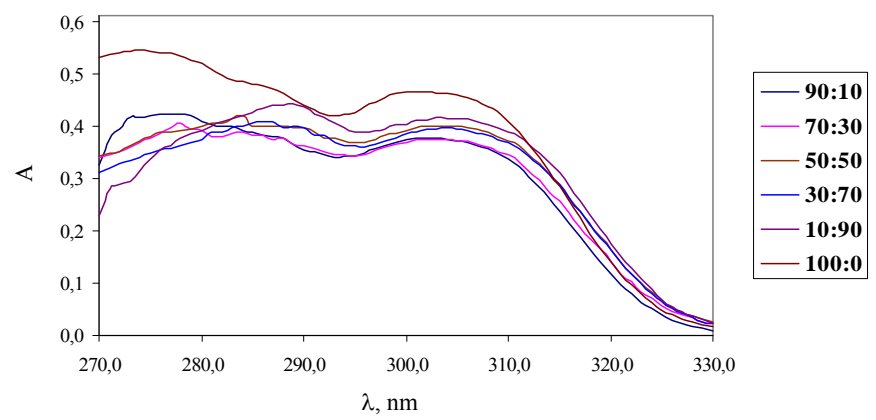

Figure 6. Absorption spectra of NPP in mixed methanol and carbon tetrachloride solvent

The shift of the peak as a function of chloroform percent is shown in Figure 3. As the carbon tetrachloride percent increases the extent of the red shift also increases which is as a result of the increase in conjugation.

The relationship between dielectric constant and molar absorptivity is shown in Figure 7. The molar absorptivity increases with increasing in dielectric constant of the solvent.

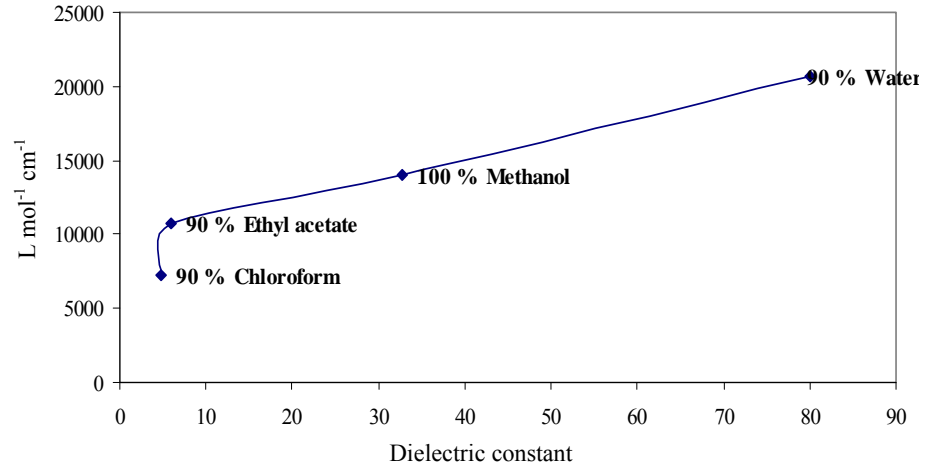

Figure 7. The relationship between dielectric constant and molar absorptivity 


\section{Conclusion}

The absorption spectra of the bichromophore NPP in mixed solvents shows two peaks at 274 $\mathrm{nm}$ and $302 \mathrm{~nm}$ which are the result of $\pi \rightarrow \pi^{*}$ transitions. The peak at $274 \mathrm{~nm}$ was exhibited a blue shift with increasing in its intensity. This is attributed to solvent-solute interactions in terms of hydrogen bonding effects. However, a red shift and decreasing in its intensity of the peak at $302 \mathrm{~nm}$ was observed, due to the dielectric properties of polar mixed solvents.

The lone pair of electron on the nitrogen atom contributes strongly on the conjugation system of the pyridine and pyrazole which makes $\pi \rightarrow \pi^{*}$ transitions to occur at lower energy. The ability of this lone pair to form hydrogen bond with the solvent reduces this contribution and therefore makes $\pi \rightarrow \pi^{*}$ transitions to occur at higher energy.

\section{References}

1. Kashiwame Y, Watanabe M, Araki K, Kuwata S and Ikariya T, Bull Chem Soc Jpn., 2011, 84(3), 251

2. Trofimenko S, Scorpionates: The Coordination Chemistry of Polypyrazolylborate Ligands, Imperial College Press, London, 1999.

3. Büchel G E, Stepanenko I N, Hejl M, Jakupec M A, Arion V B and Keppler B K, Inorg Chem., 2009, 48, 10737-10747.

4. Chi Y and Chou P T, Chem Soc Rev., 2010, 39, 638.

5. $\quad$ Najar A M and Ward M D, Inorg Chem-An Indian J., 2013, 8(1), 11.

6. Kitagawa S, Kitaura R and Noro S, Angew Chem Int Ed., 2004, 43, 2334-2375.

7. Zhao X, Xiao B, Fletcher A J, Thomas K M, Bradshaw D and Rosseinsky M J, Science, 2004, 306, 1012-1015.

8. Tong M L, Wu Y M, Ru J, Chen X M, Chang H C and Kitagawa S, Inorg Chem., 2002, 41, 4846-4848.

9. Homocianu M, Airinei A and Dorohoi D O, J Adv Res Phys., 2011, 2(1), 1.

10. Zakerhamidi M S, Ghanadzadeh A and Moghadam M, Chem Sci Trans., 2012, 1(1), 1-8; DOI:10.7598/cst2012.118

11. Adeogun A I, Odozi N W, Obiegbedi N O and Bello O S, Afr J Biotechnol., 2008, 7(15), 2736

12. Geetanjali, and Ram Singh, Arch Appl Sci Res., 2013, 5(1), 259.

13. Sancho I M, Almandoz M C, Blanco S E and Castro E A, Int J Mol Sci., 2011, 12, 8895-8912.

14. Amrallah A H, Abdalla N A and El-Haty E Y, J Chin Chem Soc., 2006, 53, 697-706.

15. Airinei A, Homocianu M and Dorohoi D O, J Mol Liq., 2010, 157, 13-17.

16. Knowles A and Burgess C, Practical Absorption Spectrometry - UV Spectrometry Group, Chapman and Hall, 1984. 